\title{
RANCANG BANGUN SISTEM INJEKSI YODIUM PADA MESIN SCREW DAN MIXER GARAM SESUAI SNI 3556
}

\author{
Ridlo Edy Sulistiyo \\ Program Studi Teknik Mesin, Fakultas Teknik \\ Universitas Muria Kudus \\ Email : 201454077@std.umk.ac.id \\ Masruki Kabib \\ Program Studi Teknik Mesin, Fakultas Teknik \\ Universitas Muria Kudus \\ Email : masruki.kabib@umk.ac.id \\ Rochmad Winarso \\ Program Studi Teknik Mesin, Fakultas Teknik \\ Universitas Muria Kudus \\ Email : Rochmad.Winarso@umk.ac.id
}

\begin{abstract}
ABSTRAK
Garam merupakan kebutuhan yang sangat penting bagi kehidupan manusia. Garam yang digunakan sebagai bahan olahan makanan memerlukan standar khusus yang dikenal sebagai standar garam konsumsi. Garam konsumsi adalah garam yang telah mengandung senyawa yodium 30-50 ppm sesuai dengan Standar Nasional Indonesia. Proses pencampuran garam dengan yodium yang masih dilakukan secara manual dikembangkan menjadi sistem injeksi atau spray pada dua tahapan yaitu pada mesin screw dan mixer garam, dengan tujuan agar dapat menyemprot larutan $\mathrm{KIO}_{3}$ secara merata sesuai kebutuhan pencampuran sehingga memperoleh hasil garam konsumsi yang homogen dan sesuai dengan SNI. Metodologi pelaksanaan yang digunakan dalam perancangan alat injeksi yodium meliputi tinjauan pustaka, analisa kebutuhan, perancangan alat, simulasi aliran, pembuatan alat dan pengujian alat. Dari hasil perancangan sistem injeksi yodium menghasilkan data perhitungan flowrate nozel sebesar $6,94 \times 10^{-6} \mathrm{~m}^{3} / \mathrm{s}$, kecepatan aliran 0,138 $\mathrm{m} / \mathrm{s}$, tekanan kebutuhan pompa $200156,432 \mathrm{~N} / \mathrm{m}^{2}$ dan daya pompa 68,5 watt. Pada simulasi software Engineering Design didapatkan hasil kecepatan aliran nozel sebesar 0,195 m/s. Hasil pengujian sistem mekanik dan sistem injeksi menunjukkan bahwa garam yang telah diiodisasi meliputi uji kadar iodium berdasarkan warna larutan iodat tester pada garam menunjukkan hasil warna ungu tua yang menunjukkan kadar yodium $44,5 \mathrm{ppm}$ dan memenuhi persyaratan SNI No.01-3556-2000.
\end{abstract}

Kata kunci : Yodium, Iodisasi, Sistem injeksi yodium, Mesin mixer

\section{ABSTRACT}

Salt is a very important need for human life. Salt used as food processing materials requires special standards known as consumption salt standards. Consumption salt is salt which has 30-50 ppm iodine compounds in accordance with Indonesian National Standards. The process of mixing salt with iodine which is still done manually is developed into an injection or spray system in two stages, namely the screw machine and salt mixer, with the aim to be able to spray $\mathrm{KIO}_{3}$ solution evenly according to the mixing needs so as to obtain a homogeneous consumption of salt and in accordance with SNI. The implementation methodology used in the design of iodine injection tools includes literature review, needs analysis, tool design, flow simulation, tool making and tool testing. From the results of iodine injection system design, the data of flowrate nozzle calculation is $6.94 \times 10-6 \mathrm{~m}^{3} / \mathrm{s}$, flow rate is $0.138 \mathrm{~m} / \mathrm{s}$, pump pressure is $200156.432 \mathrm{~N} / \mathrm{m}^{2}$ and pump power is 68.5 watts. In the Engineering Design software simulation, the result of nozzle flow velocity is $0.195 \mathrm{~m} / \mathrm{s}$. The results of the testing of the mechanical system and injection system indicate that the iodized salt includes iodine content based on the color of the iodate tester on the salt which shows a dark purple color which shows iodine content of 44,5 ppm and meets the requirements of SNI No. 01-3556-2000.

Keywords : Iodine, Iodization, Iodine Injection System, Mixer Machine 


\section{PENDAHULUAN}

Seiring berkembangnya waktu garam merupakan kebutuhan yang sangat penting bagi manusia. Garam dibutuhkan sebagai bahan pengawet makanan ataupun bumbu masak yang dikonsumsi oleh manusia. Proses pembuatan garam rakyat adalah suatu proses menguapkan air laut dalam petak-petak tambak garam di pinggir pantai. Air laut yang diuapkan sampai kering mengandung setiap liternya 7 mineral yaitu $\mathrm{CaSO} 4, \mathrm{MgSO} 4, \mathrm{MgCl} 2, \mathrm{KCl}, \mathrm{NaBr}, \mathrm{NaCl}$, dan air dengan berat total 1025,68 gram. Setelah dikristalkan pada proses selanjutnya maka akan diperoleh garam dengan kepekatan 16,75-28,5 Be setara dengan 23,3576 gram.[1]

Keputusan Presiden Nomor 69 tahun 1994 tentang pengadaan garam beriodium, menegaskan bahwa garam yang dapat diperdagangkan bagi keperluan konsumsi manusia, pengawetan makanan atau bahan penolong industri pangan, adalah garam beriodium yang telah memenuhi Standar Nasional Indonesia dan berdasarkan SNI Nomor 01-3566-2000 dengan batas kandungan iodium dalam garam adalah minimum $30 \mathrm{mg} / \mathrm{kg}$ (ppm).[2]

Kandungan senyawa pembentuk garam beryodium yang sesuai dengan SNI 3556 dapat dilihat pada tabel 1 berikut :

Tabel 1. Kandungan senyawa pembentuk garam beryodium sesuai SNI 3556 [3]

\begin{tabular}{|c|c|c|c|}
\hline No & Nama kandungan & Ukuran & Nilai SNI \\
\hline 1 & $\mathrm{NaCl}$ & $(\%)$ & 94,7 \\
\hline 2 & $\operatorname{Air}\left(\mathrm{H}_{2} \mathrm{O}\right)$ & $(\%)$ & $\operatorname{Max} 7$ \\
\hline 3 & Iodium (dihitung sebagai $\mathrm{K} \mathrm{O}_{3}$ ) & $(\mathrm{mg} / \mathrm{kg})$ & $30-80$ \\
\hline 4 & $\mathrm{Fe}_{2} \mathrm{O}_{3}$ & $(\mathrm{mg} / \mathrm{kg})$ & Max 100 \\
\hline 5 & $\mathrm{Ca}$ (dihitung sebagai $\mathrm{Ca}^{++}$) & $(\%)$ & $\operatorname{Max} 1,0$ \\
\hline 6 & $\mathrm{Mg}$ (dihitung sebagai $\mathrm{Mg}^{++}$) & $(\%)$ & \\
\hline 7 & $\mathrm{SO}_{4}$ & $(\%)$ & $\operatorname{Max} 2,0$ \\
\hline 8 & Bagian yang tidak larut dalam cemaran logam & $(\%)$ & $\operatorname{Max} 0,5$ \\
\hline 9 & $\mathrm{~Pb}$ & $(\mathrm{mg} / \mathrm{kg})$ & $\operatorname{Max} 10$ \\
\hline 10 & $\mathrm{Cu}$ & $(\mathrm{mg} / \mathrm{kg})$ & $\operatorname{Max} 10$ \\
\hline 11 & $\mathrm{Hg}$ & $(\mathrm{mg} / \mathrm{kg})$ & Max 0,1 \\
\hline 12 & As & $(\mathrm{mg} / \mathrm{kg})$ & $\operatorname{Max} 0,1$ \\
\hline 13 & Anti kempal & & Max 5 \\
\hline 14 & Kalium ferro sinadia & & Max 5 \\
\hline
\end{tabular}

Garam beriodium adalah garam yang telah diperkaya atau telah mengalami fortifikasi (ditambah) dengan $\mathrm{KIO}_{3}$ (Kalium Iodat) sebanyak 30-80 ppm.[4] Teknologi iodisasi garam ditemukan pada tahun 1921 di Swiss ketika waktu itu sekitar $70 \%$ anak-anak menderita gangguan akibat kekurangan iodium. Di Indonesia sendiri sudah menjadi kewajiban produsen garam untuk menambahkan 30-80 ppm iodium ke dalam garam.[5]

Iodium merupakan salah satu mikronutrien yang sangat penting untuk tubuh manusia. Kekurangan iodium dapat menyebabkan gangguan yang dikenal dengan GAKI (gangguan akibat kekurangan iodium) seperti terjadinya pembesaran kelenjar gondok, gangguan mental dan gangguan kecerdasan.

Proses pembuatan garam beriodium secara manual yang ada saat ini, dilakukan dengan cara mengaduk bolak-balik setumpuk garam yang telah disemprotkan larutan iodat ke dalam garam tersebut pada konsentrasi tertentu, misalnya konsentrasi 4\% dalam jumlah $100 \mathrm{ml}$ untuk kebutuhan $100 \mathrm{~kg}$ garam, sehingga akan diperoleh kandungan $\mathrm{KIO}_{3}$ dalam garam tersebut sebesar 40 ppm.[6]

Perancangan alat iodisasi garam sistem semi otomatis dengan kapasitas alat $120 \mathrm{~kg} / \mathrm{jam}$, konsumsi daya listrik 800 watt (4 amper) dan kapasitas larutan penyemprot 1 liter untuk industri kecil. Alat ini bersifat portable dan vertikal dengan bentuk mixer silinder digunakan untuk 
mengaduk garam dan $\mathrm{KIO}_{3}$ yang akan diiodisasi menggunakan sistem pompa dan motor listrik 1 HP.[7]

Proses iodisasi garam skala besar umumnya menggunakan sistem kontinyu dengan cara penyemprotan larutan $\mathrm{KIO}_{3}$ garam menggunakan sebuah kompresor kepermukaan garam yang

berjalan diatas sebuah ban berjalan (conveyer belt) dan langsung dikeringkan menggunakan udara panas [8], namun peralatan tersebut memerlukan modal yang besar dan hanya dapat dioperasikan untuk proses iodisasi garam skala besar.

Untuk mengatasi permasalahan diatas, maka perlu perancangan suatu alat iodisasi garam dengan sistem injeksi yang dapat menyemprot $\mathrm{KIO}_{3}$ sesuai dengan takaran yang telah ditentukan. Sistem injeksi dipilih karena cairan yang disemprotkan dapat menyebar secara merata dan tidak tercecer. Disamping itu alat ini juga dirancang untuk menyemprotkan $\mathrm{KIO}_{3}$ (yodium) pada 2 proses, yaitu proses injeksi pada mesin screw dan mesin mixer garam, dengan tujuan dapat mencampur garam dengan yodium secara homogen dan menghasilkan garam konsumsi yang berkualitas dengan kadar yodium sesuai Standar Nasional Indonesia (SNI) juga dapat meningkatkan nilai ekonomis dari garam tersebut.

\section{METODOLOGI PERANCANGAN}

Metodologi yang digunakan dalam perancangan sistem injeksi yodium pada mesin screw dan mixer garam seperti terlihat pada gambar 1 berikut:

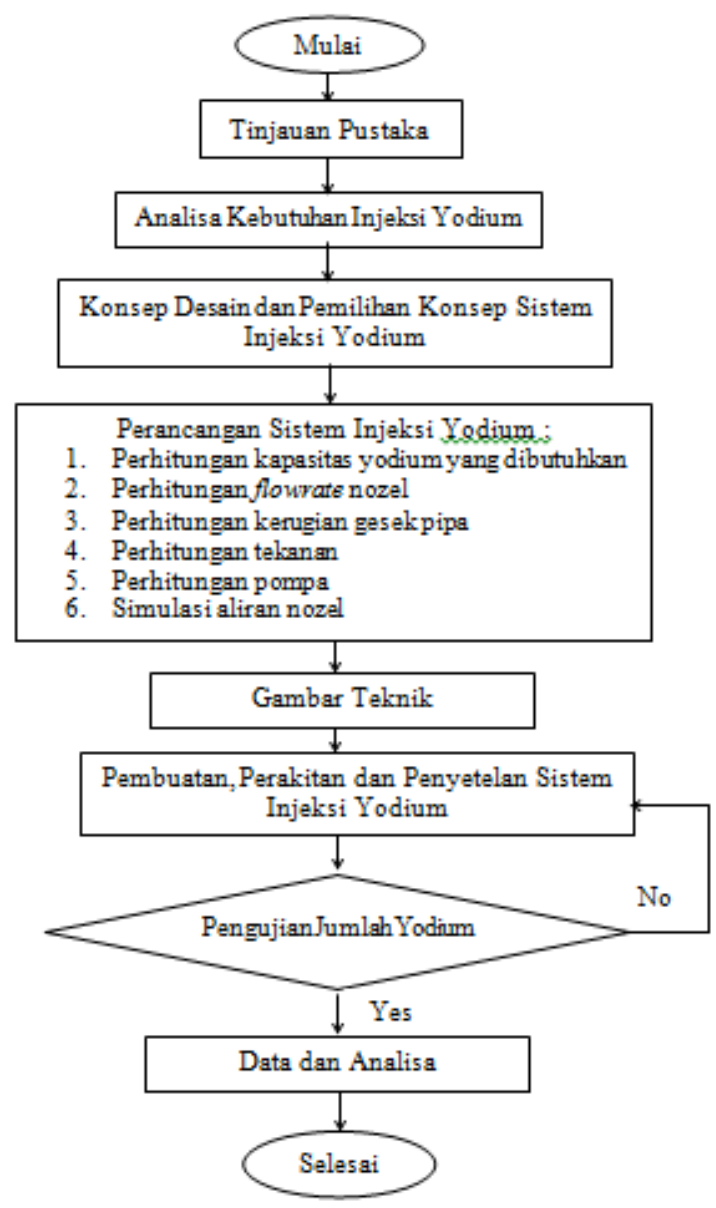

Gambar 1. Diagram Alir 
Metodologi perancangan sistem injeksi yodium diatas dimulai dari mencari sumber-sumber tinjauan pustaka yang digunakan sebagai acuan dalam perancangan sistem injeksi yodium, dilanjutkan analisa kebutuhan meliputi : aspek teknik, aspek manufaktur, aspek ekonomi dan aspek keselamatan kerja. Dari analisa kebutuhan dihasilkan sebuah konsep desain yang dirancang sesuai kebutuhan perancangan.

Dari beberapa konsep desain sistem injeksi yodium, dapat disimpulkan pemilihan konsep yang paling efisien sesuai observasi dan analisa kebutuhan, kemudian dilakukan perancangan sistem injeksi yodium meliputi : perhitungan kebutuhan larutan $\mathrm{KIO}_{3}$, perhitungan flowrate nozel, perhitungan kecepatan aliran, perhitungan kerugian gesek, perhitungan tekanan pompa dan perhitungan daya pompa.

Setelah perancangan sistem injeksi yodium dihasilkan gambar kerja dan dilakukan proses pembuatan komponen meliputi : pembuatan box tangki yodium dan pembuatan dudukan nozel, kemudian dilakukan proses perakitan semua komponen agar menjadi kesatuan sistem yang bekerja secara optimal.

Proses pengujian sistem injeksi yodium merupakan proses yang paling penting untuk mengetahui kondisi alat tersebut apakah bekerja sesuai perancangan atau tidak, apabila dari hasil pengujian tersebut belum sesuai perancangan dapat dilakukan perbaikan sehingga dapat bekerja secara efektif dan efisien.

\section{HASIL DAN PEMBAHASAN}

Sistem pencampuran $\mathrm{KIO}_{3}$ dengan garam krosok yang sudah dicuci pada perancangan ini di desain untuk mengatasi permasalahan para petani yang mencampur garam secara manual. Sistem injeksi ini dipilih agar diharapkan proses pencampuran yang terjadi memiliki tingkat homogen yang tinggi, sehingga garam yang dihasilkan dapat memenuhi standar nasional yang sudah ditetapkan.

Adapun hasil dari proses rancang bangun sistem injeksi yodium ini meliputi pemilihan konsep desain yang sesuai dengan analisa kebutuhan dapat dilihat pada gambar 2 berikut :

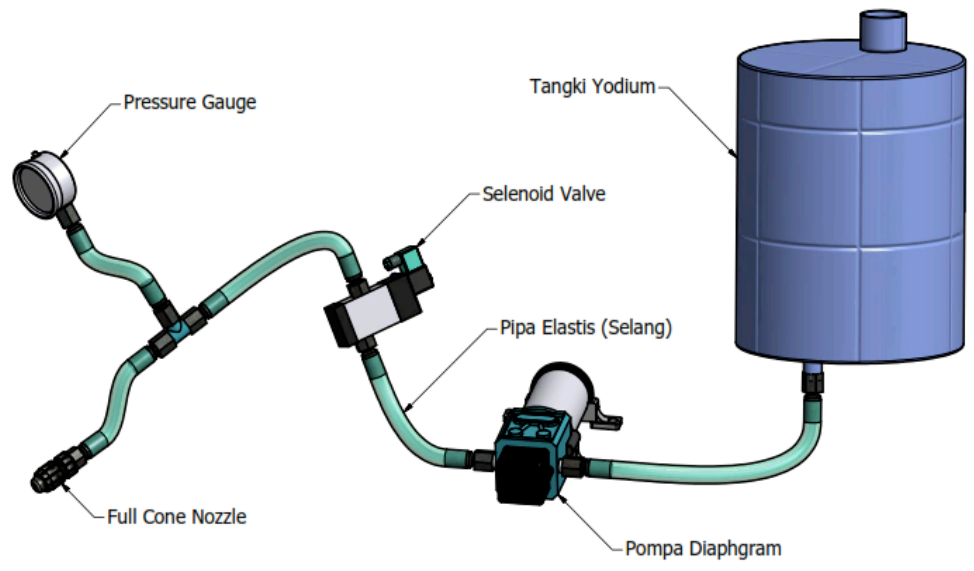

Gambar 2. Sistem Injeksi Full Cone Nozzle

Komponen-komponen sistem injeksi yodium pada gambar 2 memiliki fungsi yang berbedabeda, meliputi : Nozel berfungsi untuk memecah dan mengatur pola semprotan cairan yodium dalam mesin screw dan mixer garam, Selenoid valve berfungsi sebagai sistem kontrol pengaturan on-off dari sistem tersebut, Tangki yodium digunakan untuk menampung cairan yodium atau $\mathrm{KIO}_{3}$, Pulse width modulation (PWM) berfungsi sebagai pengatur tekanan yang dibutuhkan oleh sistem sesuai dengan kebutuhan, Pressure gauge berfungsi sebagai pengukur tekanan aliran yang 
masuk melalui pipa elastis menuju ke nozel dan Pompa diaphgram berfungsi sebagai sumber utama penghasil tekanan atau pemindah cairan untuk menjalankan sistem injeksi.

Mekanisme kerja dari sistem injeksi yodium tersebut adalah dimulai dari membuat takaran $\mathrm{KIO}_{3}$ pada tahap pencampuran mesin screw dan mesin mixer garam sebesar 50 ppm, yaitu untuk $100 \mathrm{~kg}$ garam kalium iodatnya yang diperlukan 5 gram, larutan air panas sebesar 0,125 L, dan larutan air Ades 0,250 L. Garam krosok masuk ke dalam mesin screw dan sistem injeksi bekerja menyemprot cairan yodium sebesar $30 \mathrm{ppm}$. Setelah dari mesin screw, diteruskan menuju mesin mixer dan sistem injeksi juga bekerja secara bersamaan dengan mesin mixer, cairan yodium yang disemprotkan sebesar $20 \mathrm{ppm}$. Sistem injeksi bekerja menggunakan tekanan dari pompa yang tekanannya sudah diatur oleh PWM sesuai dengan kebutuhan. Cairan yodium dari pompa akan melewati selenoid valve (sebagai pengaturan on-off), kemudian melewati pressure gauge (sebagai pengukur tekanan di dalam selang) dan menuju ke nozel (sebagai pengkabutan yodium). Setelah melalui 2 proses tersebut, diharapkan pencampuran garam dengan yodium menghasilkan garam konsumsi yang memenuhi standar SNI 3556 dengan mengandung kadar yodium minimal 50 ppm.

\subsection{Kebutuhan Yodium atau $\mathrm{KIO}_{3}$}

Untuk mendapatkan kandungan yodium pada garam sebesar 50 ppm, maka perancangan kebutuhan larutannya adalah : jika diasumsikan untuk $100 \mathrm{~kg}$ garam diperlukan Kalium Iodat $\left(\mathrm{KIO}_{3}\right)=5$ gram, Air panas $=0,125 \mathrm{~L}$, Larutan air ades $=0,250$ L. [2]

\subsection{Perancangan Sistem Injeksi Yodium}

Sistem injeksi merupakan sistem penyemprotan cairan dengan menggunakan nozel yang berfungsi untuk memecah fluida menjadi butiran tetesan yang kecil. sistem ini digunakan untuk mencampur garam pada mesin screw dan mixer dengan sistem kerja secara injeksi atau spray.

Perhitungan dalam perancangan sistem injeksi yodium adalah perhitungan untuk mencapai kandungan yodium 50 ppm meliputi perhitungan kecepatan aliran, flowrate nozel, kerugian gesek, tekanan dan daya pompa.

Adapun hasil dari perancangan sistem injeksi yodium dapat dilihat pada tabel 2 berikut :

Tabel 2. Hasil perhitungan sistem injeksi yodium

\begin{tabular}{lcc}
\hline \multicolumn{1}{c}{ Perhitungan } & Rumus & Hasil \\
\hline Kebutuhan larutan $\mathrm{KIO}_{3}$ & $V=\frac{m}{\rho}$ & $0,376 \mathrm{~L}$ \\
Flowrate nozel & $\mathrm{Q}=\mathrm{A} \cdot \mathrm{v}$ & $6,94 \times 10^{-6} \mathrm{~m}^{3} / \mathrm{s}$ \\
Kecepatan aliran & $v=\frac{{ }^{2}}{\frac{\pi}{4} \cdot d^{2}}$ & $0,138 \mathrm{~m} / \mathrm{s}$ \\
Kerugian gesek & $h_{f}=f \frac{L}{D} \cdot \frac{v^{2}}{2 g}$ & $0,217 \mathrm{~m}$ \\
Kerugian tekanan & $h_{p}=\frac{1}{9,8} \cdot \frac{p^{\prime}}{\rho}$ & $2,4 \mathrm{~N} / \mathrm{m}^{2}$ \\
Tekanan pompa & $P=\frac{1}{2} \rho v_{2}+\rho g H$ & $200156,432 \mathrm{~N} / \mathrm{m}^{2}$ \\
Daya pompa & $\cdot \mathcal{W}_{p}=W_{p} x m$ & $68,5 \mathrm{watt}$ \\
\hline
\end{tabular}




\subsection{Simulasi Kecepatan Aliran Nozel}

Bagian atau komponen dari sistem injeksi yodium yang penting adalah nozel, dimana nozel sebagai komponen yang berfungsi menyemprotkan cairan. Maka dari itu dilakukan simulasi kecepatan aliran pada nozel menggunakan software Engineering Design.

Hasil dari simulasi kecepatan aliran pada nozel dapat dilihat pada gambar 3 berikut:

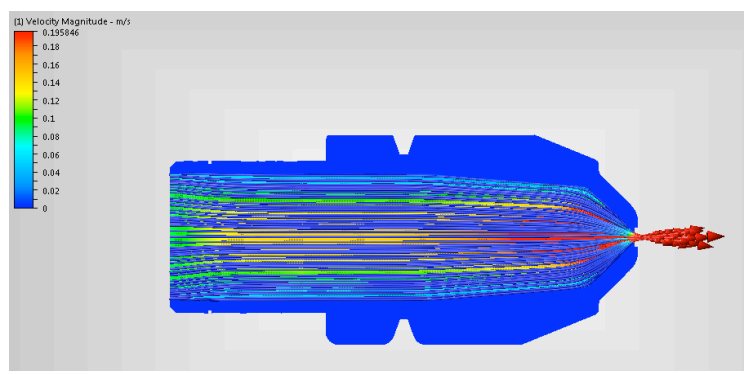

Gambar 3. Hasil simulasi kecepatan aliran nozel

Hasil dari gambar simulasi software Engineering Design adalah bahwa kecepatan aliran input nozel sebesar $0,08 \mathrm{~m} / \mathrm{s}$ dan output dari nozel sebesar $0,195 \mathrm{~m} / \mathrm{s}$.

\subsection{Proses Manufaktur Dan Perakitan Alat}

Dalam pembuatan sistem injeksi yodium melalui beberapa langkah permesinan untuk pembuatan komponen. Setelah perancangan dan simulasi dilakukan tahap selanjutnya yaitu membaca dan mempelajari gambar kerja dengan menyesuaikan hasil rancangan desain mesin dengan gambar kerja yang telah dibuat. Adapun proses-proses dalam pembuatan komponen sistem injeksi yodium meliputi : pembuatan box yodium dan dudukan nozel. Pembuatan box yodium menggunakan material Besi ST 37 bentuk siku ukuran $30 \mathrm{~mm}$ x $30 \mathrm{~mm}$ x 2,5 dengan dimensi ukuran pada gambar 4, sedangkan pembuatan dudukan nozel menggunakan material poros SS 304 dengan dimensi ukuran pada gambar 5 berikut :
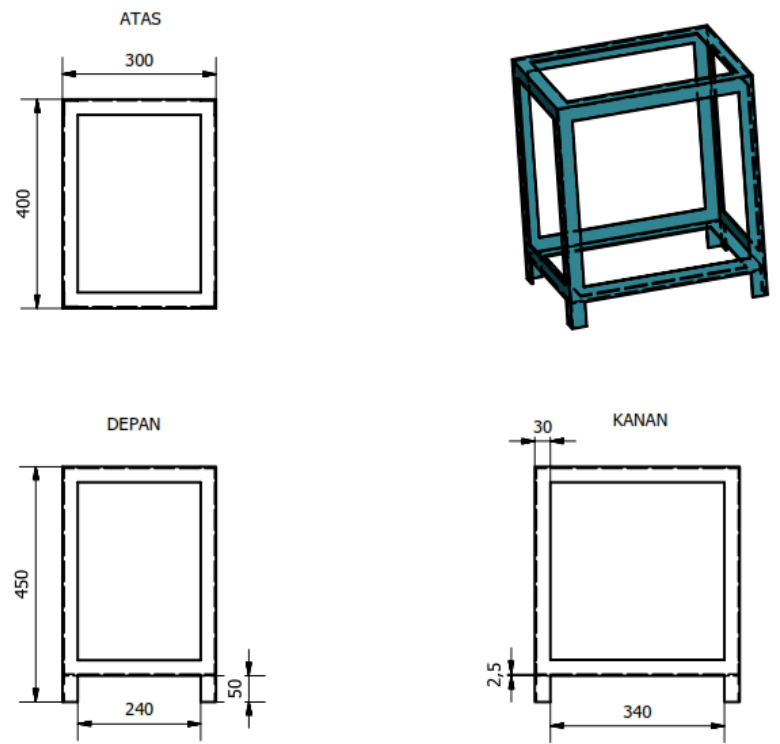

Gambar 4. Dimensi rangka box yodium 


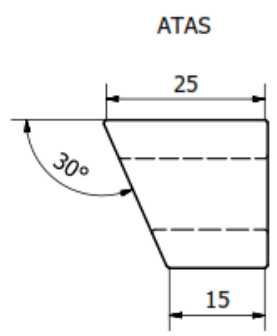

KANAN

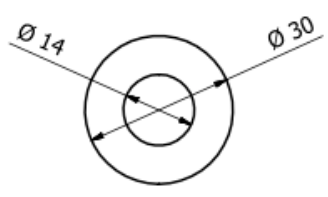

Gambar 5. Dimensi dudukan nozel

Adapun perhitungan proses pembuatan box yodium dan dudukan nozel dapat dilihat pada tabel 3 berikut :

Tabel 3. Hasil perhitungan proses manufaktur sistem injeksi yodium

\begin{tabular}{|c|c|c|}
\hline Perhitungan & Rumus & Hasil \\
\hline \multirow{4}{*}{$\begin{array}{l}\text { Pengelasan box } \\
\text { yodium }\end{array}$} & $\begin{array}{l}A=a . I \\
\text { total panjang kampuh }(\mathrm{mm})\end{array}$ & $2400 \mathrm{~mm}^{2}$ \\
\hline & panjang per 1 menit (mm) & 6,5 menit \\
\hline & total panjang kampuh $(\mathrm{mm})$ & 7 batang \\
\hline & panjang per 1 batang $(\mathrm{mm})$ & \\
\hline \multirow{3}{*}{ Pembubutan } & $n=\frac{v \cdot 1000}{\pi \cdot d}$ & $360 \mathrm{rpm}$ \\
\hline & $f=0,084 \sqrt[3]{d}$ & $0,26 \mathrm{~mm} / \mathrm{put}$ \\
\hline & $t_{c}=\frac{l_{t}}{V_{f}}$ & 0,34 menit \\
\hline \multirow{3}{*}{ Pengeboran } & $n=\frac{V .1000}{\pi . d}$ & $300 \mathrm{rpm}$ \\
\hline & $f=0,084 \sqrt[3]{d}$ & $0,20 \mathrm{~mm} / \mathrm{put}$ \\
\hline & $t_{c}=\frac{I_{t}}{V_{f}}$ & 1,02 menit \\
\hline
\end{tabular}

Proses assembling merupakan proses perakitan/penggabungan beberapa komponen yang bertujuan untuk membentuk sistem injeksi yodium yang masih terpisah-pisah antar bagiannya, untuk disatukan menjadi kesatuan alat yang bekerja sesuai dengan fungsi dan cara kerjanya. 


\subsection{Pengujian Kadar Yodium}

Proses pengujian merupakan langkah yang penting dalam pembuatan sebuah mesin pencampur garam dengan yodium khususnya pada sistem injeksi, yaitu agar dapat mengetahui apakah mesin tersebut dapat bekerja secara efektif sesuai perancangan atau tidak. Adapun hasil dari pengujian yang sudah dilakukan dapat dilihat pada tabel 4 berikut :

Tabel 4. Hasil pengujian pencampuran garam dengan yodium

\begin{tabular}{ccccc}
\hline No & Garam (kg) & Jumlah cairan (mL) & Waktu (menit) & $\begin{array}{c}\text { Kadar yodium } \\
\text { (ppm) }\end{array}$ \\
\hline $\mathbf{1}$ & $25 \mathrm{~kg}$ & $50 \mathrm{~mL}$ & 1 menit & $44,5 \mathrm{ppm}$ \\
$\mathbf{2}$ & $25 \mathrm{~kg}$ & $50 \mathrm{~mL}$ & 1 menit & $44,34 \mathrm{ppm}$ \\
$\mathbf{3}$ & $25 \mathrm{~kg}$ & $50 \mathrm{~mL}$ & 1 menit & $44,7 \mathrm{ppm}$ \\
\hline
\end{tabular}

Dari hasil pengujian pada tabel 4 dapat disimpulkan bahwa setelah melaui proses pengujian menggunakan metode titrasi iodometri, kadar yodium dalam garam krosok yang awalnya 0 ppm meningkat menjadi $44,5 \mathrm{ppm}$ sesuai perancangan alat dan memenuhi syarat garam konsumsi Standar Nasional Indonesia.

\section{KESIMPULAN}

Dari perancangan dan pengujian sistem injeksi yodium yang sudah dilakukan, dapat disimpulkan sebagai berikut :

Sistem injeksi menggunakan nozel sebagai pemecah cairan yang di suplai dari tekanan pompa diaphgram dengan tekanan $200156,432 \mathrm{~N} / \mathrm{m}^{2}$, daya pompa 68,5 watt, flowrate nozel sebesar $6,94 \times 10^{-6} \mathrm{~m}^{3} / \mathrm{s}$ dengan kecepatan aliran $0,138 \mathrm{~m} / \mathrm{s}$.

Proses simulasi software Engineering Design pada komponen nozel dengan analisa kecepatan nozel mendapatkan hasil simulasi kecepatan aliran sebesar $0,195 \mathrm{~m} / \mathrm{s}$ menunjukkan bahwa hasil perhitungan manual dengan hasil simulasi mendekati atau sesuai dengan kebutuhan perancangan.

Hasil pengujian sistem mekanik dan sistem injeksi menunjukkan hasil pengujian garam yang telah diiodisasi meliputi uji kadar iodium pada garam menunjukkan hasil kadar yodium 44,5 ppm menggunakan metode titrasi iodometri dan sudah memenuhi persyaratan SNI No.01-3556-2000.

\section{DAFTAR PUSTAKA}

[1] Warniati, "Peningkatan Kualitas Garam dengan Serbuk Kapur Padam," Pros. Semin. Tek. Kim., 1997.

[2] S. N. Indonesia, Garam Konsumsi Beriodium. Jakarta: Badan Standardisasi Nasional, 2000.

[3] S. N. Indonesia, Syarat Mutu Garam Konsumsi Beryodium. Badan Standardisasi Nasional, 2010.

[4] A. Komari, Y., Herlinda, E. A. dan Murdiana, Encapsulation of iodine and iron for double fortification of foods for combating Iodine Deficiency Disorder (IDD) and Iron Deficiency Anemia (IDA). Research Report Natioanl Institute for Health Research and Development WHO, 1995.

[5] I. N. L. Soeid, "Kekuatan Dibalik Garam Fortifikasi," 2005.

[6] A. Ilham, M. Z., Sabri and Aryad, "Rancang Bangun Mesin Iodisasi Garam Berpengaduk," Makassar, 2009.

[7] Mahllinda and L. Maurina, "Rancang Bangun Peralatan Iodisasi Garam Portabel Menggunakan Sistem Semi Otomatis,” Has. Penelit. Ind., vol. 26, No. 2, pp. 73-80, 2013.

[8] W. Holman J.C.M., McCartney, Iodized Salt. London: Chilean Iodine Educational Bureau, 1996. 